\title{
A ANÁLISE ECONÔMICA DO DIREITO NO TRIBUNAL DE JUSTIÇA DO RIO GRANDE DO SUL: UM ESTUDO SOBRE O CASO DOS FUMICULTORES E AS CONCESSIONÁRIAS DE ENERGIA ELÉTRICA
}

\section{Ana Elizabeth Neirão Reymão*}

Doutora em Ciências Sociais (UnB), Mestre em Economia (UNICAMP), Economista (UFPA), professora do Programa de Pós-Graduação em Direito, Políticas Públicas e Desenvolvimento Regional (PPGD-CESUPA) e da Faculdade de Economia (UFPA).

\section{Karla Azevedo Cebolão**}

Mestre em Direito, Políticas Públicas e Desenvolvimento Regional (PPGD-CESUPA). Bacharel em Economia e Direito. Servidora do Tribunal de Justiça (PA). Professora da Faculdade de Belém (FABEL).

\section{RESUMO}

O artigo objetiva discutir decisões judiciais que empregam a Análise Econômica do Direito (AED), apresentando um estudo de caso sobre o litígio entre os fumicultores gaúchos e as concessionárias de energia elétrica, no Tribunal de Justiça do Estado do Rio Grande do Sul (TJRS). A pesquisa é de abordagem qualitativa, com levantamento bibliográfico e documental, notadamente a jurisprudência sobre o tema. Mostra-se que, desde fins de 2016, essas disputas judiciais têm sido decididas com base em conceitos da AED, concluindo o TJRS pela divisão do prejuízo entre os fumicultores e as concessionárias.

Palavras-chave: Análise Econômica do Direito. Dever de mitigar os prejuízos. Eficiência. Evitador de maior custo. Fórmula Hand. Jurisprudência.

Economic Analysis of the Law in Rio Grande do Sul court of justice: a study on the case of the tobacco producers and the electricity concessionaires

\begin{abstract}
The paper discusses judicial decisions based on Economic Analysis of Law (AED), presenting a case study on the litigation between tobacco farmers and concessionaires of electric energy, at the Court of Justice of the State of Rio Grande do Sul (TJRS). The research is qualitative approach, with a bibliographical and documentary survey, especially the jurisprudence on the subject. Since the end of 2016, these legal disputes have been decided based on concepts of the AED, concluding the TJRS for the division of the damages between tobacco growers and concessionaires.
\end{abstract}

Keywords: Economic Analysis of Law. Duty to mitigate the loss. Efficiency. Cheapest cost avoider. Hand Formula. Jurisprudence.

\footnotetext{
* Endereço: Rua dos Mundurucus, 4183. Bairro: São Braz, CEP: 66073-005, Belém - Pará. Email: bethrey@uol.com.br.

** Endereço: Av. Nazaré, 617, apto 901. Bairro: Nazaré, CEP: 66035-135, Belém - Pará. E-mail: karlacebolao@yahoo.com.br.

Rev. de Direito, Economia e Desenvolvimento Sustentável | e-ISSN: 2526-0057| Goiânia| v. 5 | n. 1 | p. 1-22| Jan/Jun. 2019
} 


\section{1- Introdução}

O artigo objetiva discutir decisões judiciais que empregam a Análise Econômica do Direito (AED), apresentando um estudo de caso sobre o litígio entre os fumicultores gaúchos e as concessionárias de energia elétrica, no Tribunal de Justiça do Estado do Rio Grande do Sul (TJRS).

O Brasil é um grande produtor mundial e exportador de tabaco, sendo o estado responsável por expressivo percentual do volume nacional. Várias usinas de beneficiamento de tabaco lá se concentram.

No início da cadeia de valores dessa indústria tem-se a produção baseada na agricultura familiar, envolvendo cerca de 80 mil famílias e 88 mil estufas de fumo (RIO GRANDE DO SUL, 2015).

Esses produtores têm sido sistematicamente afetados pela interrupção do fornecimento de energia elétrica no momento da secagem das plantas de fumo nas suas estufas. Assim, buscam o ressarcimento dos prejuízos de perda da safra, ou desvalorização do produto pelos compradores, em inúmeras ações de indenização ajuizadas no TJRS.

Até 2016 essas disputas judiciais tinham elevada probabilidade de sucesso para o fumicultor, sendo, diversas vezes, concedido o direito à indenização dos mesmos, sob a fundamentação do art. $37, \S 6^{\circ}$, da $\mathrm{CF} / 88$, e do art. 22 do Código de Defesa do Consumidor (CDC).

Mais recentemente, os casos têm sido decididos com base em conceitos da Análise Econômica do Direito (AED), expressando a preocupação do TJRS com as externalidades negativas decorrentes do pagamento, pelas concessionárias de energia elétrica, de custosos valores para indenizações dos fumicultores, o que acarretaria sua internalização na tarifa a ser paga pelos usuários do serviço no Rio Grande do Sul.

A AED privilegia a relação interdisciplinar do Direito com a Economia, especialmente quando voltada ao enfrentamento de casos judiciais específicos e complexos. Trata-se de um movimento heterogêneo que reúne várias correntes de pensamento, os quais adotam princípios semelhantes e procedimentos metodológicos

Rev. de Direito, Economia e Desenvolvimento Sustentável | e-ISSN: 2526-0057| Goiânia| v. 5 | n. 1 | p. 1-22 | Jan/Jun. 2019 
comuns: Escola de Chicago (LaE), Escola de Yale (New Haven), Teoria da Escolha Pública (Public Choice), Nova Economia Institucional, Escola Austríaca e outras abordagens instrumentais complementares, como a teoria dos jogos (FERREIRA et al., 2018).

Como explica Salama (2008), a disciplina Direito e Economia funda-se na aplicação da Economia às normas e instituições jurídico-políticas. Seus primeiros movimentos iniciaram-se na Europa, com a Escola Histórica Alemã, entre 1830 e 1930. Nos Estados Unidos (EUA), as Universidades de Chicago e Yale, foram pioneiras. A AED, depois, espalhou-se pelo país e, desde a década de 1980, vem ganhando cada vez mais visibilidade em todo o mundo, inclusive no Brasil.

Apesar de o sistema jurídico processual aqui ainda ser fortemente positivista, a AED vem crescentemente influenciando algumas decisões, como se observa no TJRS. Nessa senda, torna-se fundamental estudá-las, sendo o problema de pesquisa do presente artigo: "quais argumentos da AED têm influenciado as decisões no TJRS nos conflitos entre os produtores de fumo e as concessionárias de serviço de fornecimento de energia elétrica do estado?".

O estudo é de abordagem qualitativa, sendo o estudo de caso a técnica empregada, estratégia que aprofundará a análise sobre como a AED está presente nas referidas decisões. Os procedimentos metodológicos também envolvem o levantamento bibliográfico e a pesquisa documental, notadamente na jurisprudência do referido tribunal.

O texto está estruturado em quatro partes, incluindo essa introdução. Na seção seguinte, traz-se um panorama geral da AED. A seção três apresenta a evolução das decisões judiciais sobre o caso dos fumicultores gaúchos e as concessionárias de energia elétrica no TJRS. A parte final do texto traz as conclusões do estudo.

\section{2- A Análise Econômica do Direito: um panorama geral}

A Análise Econômica do Direito (AED) tem sido usada, em alguns tribunais brasileiros, para fundamentar decisões judiciais. Enquanto método científico, a AED

Rev. de Direito, Economia e Desenvolvimento Sustentável | e-ISSN: 2526-0057| Goiânia| v. 5 | n. 1 | p. 1-22 | 
propõe-se a avaliar, prever e guiar tais decisões face à necessidade de realizar escolhas, tendo como base a racionalidade e a busca pela eficiência. Dessa forma, pode ser útil como instrumento para a compreensão de como os sujeitos reagirão à determinada norma jurídica.

Uma das primeiras decisões utilizando de forma explícita essa metodologia foi proferida pelo Superior Tribunal de Justiça (STJ) em sede do Recurso Especial $\mathrm{n}^{\circ}$ 1163283/RS. No voto do relator, Ministro Luis Felipe Salomão, quarta turma, julgado em 07 de abril de 2015, afirma-se:

\begin{abstract}
A análise econômica da função social do contrato, realizada a partir da doutrina da análise econômica do direito, permite reconhecer o papel institucional e social que o direito contratual pode oferecer ao mercado, qual seja a segurança e previsibilidade nas operações econômicas e sociais capazes de proteger as expectativas dos agentes econômicos, por meio de instituições mais sólidas, que reforcem, ao contrário de minar, a estrutura do mercado (RIO GRANDE DO SUL, 2015, p. 3).
\end{abstract}

O magistrado considera que todo contrato de financiamento imobiliário, como os pactuados nos moldes do Sistema Financeiro da Habitação, é negócio jurídico de cunho eminentemente patrimonial e, dessa forma, passível da aplicação da AED.

No voto, o Ministro destaca as consequências do contrato, não apenas às implicações legais comumente consideradas pelos operadores do direito, mas às consequências, ao impacto do cumprimento dos contratos e da solidez das instituições nas transações (OLIVEIRA, 2015).

A AED utiliza o instrumental analítico e empírico da Economia, com ênfase na teoria microeconômica, para "compreender, explicar e prever as implicações fáticas do ordenamento jurídico, bem como, da lógica (racionalidade) do próprio ordenamento jurídico" (TIMM, 2012, p. 14).

Nesse sentido oferece, ao operador do Direito, um padrão útil para avaliar se as leis e as políticas públicas estão alcançando o objetivo social pretendido e prever os efeitos que as normas jurídicas geram sobre o comportamento humano. Com base em uma metodologia que destaca a eficiência, pode auxiliar na tomada de decisões jurídicas racionais, sobrepesando custos e benefícios ou ponderando valores sociais em conflito.

Os primeiros movimentos da AED iniciaram-se na Europa, entre 1830 e 1930, na Escola Histórica Alemã e, por meio da teoria institucionalista, chegou aos Estados 
Unidos (EUA). Embora fossem abordagens relativamente heterogêneas, buscava-se responder como a propriedade e outros direitos são determinados, funcional e historicamente, entre as diferentes sociedades. "Sua hipótese central era que o direito se subordinava às condições econômicas e sociais vigentes. Os principais autores dessas escolas são Thorstein Veblen, John R. Commons, Wesley Mitchell, Richard T. Ely e Clarence Ayres" (CEBOLÃO, 2017, p. 44-45).

Após os anos 1940, essa interação entre Direito e Economia ganhou força, quando começava a se formar a "Escola de Chicago", impulsionada pela atuação de Aaron Director, professor de economia na Faculdade de Direito da Universidade de Chicago (EUA), que utilizava conceitos econômicos aplicados a casos jurídicos (ESTEVES, 2010). Director mudou a forma de estudar o direito em Chicago, reunindo autores que se posicionavam contrários ao intervencionismo do Estado baseado no keynesianismo.

Influenciado por economistas como Friedrich Hayek, que havia recentemente publicado "O Caminho para a Servidão" (1944), e Ronald Coase, que havia publicado "The Nature of the Firm" (1937), duas ações de Director foram importantes para fortalecer os estudos nesse campo: (i) a criação do primeiro programa sobre o tema numa Faculdade de Direito e (ii) a fundação do Journal of Law and Economics, primeiro periódico científico voltado à pesquisa na área (CEBOLÃO, 2017).

Em 1960, Coase publicou "The Problem of Social Cost", reconhecido como o mais importante artigo sobre AED e o marco teórico da segunda "onda". No texto, introduziu o conceito de "custos de transação", buscando identificar os fatores que determinavam os tipos de transação e contratos que as partes celebravam. Criticando Arthur Pigou (economista inglês e um dos grandes pensadores do Welfare State), o autor mostra que o principal problema do mercado está na presença de custos de transação e não de externalidades, destacando o papel das leis e das organizações na formação e desenvolvimento dos mercados e argumentando a importância das instituições para o resultado econômico.

Em 1961, Guido Calabresi publicou "Some Thoughts on Risk Distribution and the Law of Torts", na revista da Faculdade de Direito de Yale, texto em que contribuiu para a discussão da eficiente alocação dos custos dos acidentes. O autor defendia a

Rev. de Direito, Economia e Desenvolvimento Sustentável | e-ISSN: 2526-0057| Goiânia| v. 5 | n. 1 | p. 1-22 | Jan/Jun. 2019 
proporção entre o preço dos bens e os custos totais de produção e que as atividades de risco deveriam arcar com as perdas delas decorrentes. Com base nessas ideias, "o sistema de responsabilidade civil passou a ser visto como real forma de controle das externalidades negativas" (FERREIRA et al., 2018, p. 267).

Aluno dos professores Director e Coase na Faculdade de Direito da Universidade de Chicago, Richard Posner conheceu essas ideias e passou a se dedicar ao estudo da AED, inaugurando uma nova fase nesse campo de estudo. Em 1973 publicou o livro "Economic Analysis of Law", onde destaca que o sistema de regras da Common Law servia como estímulo à conduta das pessoas para se comportarem de maneira eficiente, ou seja, passível de maximizar a riqueza na sociedade.

O autor sustentava que somente o estudo interdisciplinar de Economia e Direito habilitaria os juristas para exercer o seu ofício: a eficiência em garantir a alocação de direitos entre as partes (COELHO, 2007). Nessa primeira fase de sua teoria, a função básica do direito era alterar os incentivos, uma vez que utilizava a perspectiva econômica e de maximização da riqueza, sendo pioneiro em transferir a racionalidade da Economia para o Direito.

Em sua segunda fase, iniciada com a obra The Economics of Justice (A Economia da Justiça), Posner passou a desenvolver uma teoria de justiça "eficiente", segundo a qual "o critério para avaliar se os atos e as instituições são justas, boas ou desejáveis é a maximização de riqueza da sociedade" (POSNER, 1983, p. 115) e, ainda, que esta compreensão "permite uma reconciliação entre utilidade, liberdade, e até mesmo igualdade, como princípios éticos que (tradicionalmente) competem entre si” (POSNER, 1983, p. 115).

Dessa forma, o autor argumentava que a eficiência é o critério ético do Direito havendo, pois, uma mudança em sua análise, que passou a ter uma doutrina normativista. Assim, segundo Posner (1983), só as regras jurídicas e interpretações do direito que promovam a maximização da riqueza são consideradas justas, sendo a eficiência essencial ao Direito, uma vez que fornece um critério ético decisivo (SALAMA, 2010).

Em 1990, ele abandonou definitivamente a teoria da maximização da riqueza como fundamento ético do Direito e iniciou sua terceira fase, adotando o pragmatismo 
jurídico, defendido no livro Problemas da Filosofia do Direito. Nessa obra, afirmava que a razão humana tem limitações, sendo o conhecimento humano limitado.

Nessas diferentes fases, Richard Posner reiterava a proposta de utilizar a Economia no Direito, pretendendo que os juízes tivessem um instrumento para encontrar respostas razoáveis aos problemas jurídicos. Nesse contexto, a tomada de decisão judicial, notadamente em casos difíceis, seria orientada pela intercessão entre as duas ciências, uma vez que o pleno exercício de sua discricionariedade serviria para alcançar resultados eficientes.

A eficiência, nessa abordagem, dar-se-á pela economia de mercado e a partir de sua necessidade de auferir lucros, sendo a base das análises as escolhas racionais individuais e a maximização da satisfação, o que levaria a uma previsibilidade de escolhas.

Nos dias atuais, a AED constitui um movimento heterogêneo que congrega diversas correntes de pensamento, conectadas entre si por adotarem princípios semelhantes e procedimentos metodológicos comuns: Escola de Chicago (LaE), Escola de Yale (New Haven), Teoria da Escolha Pública (Public Choice), Nova Economia Institucional, Escola Austríaca e outras abordagens instrumentais complementares, como a teoria dos jogos (FERREIRA et al., 2018).

Observa-se, pois, que há uma ampla variedade de escolas e diferentes campos interdisciplinares em Direito e Economia, os quais influenciam tomadores de decisão, como os juízes do TJRS, análise detalhada na seção a seguir.

\section{3- Evolução das decisões judiciais sobre o caso dos fumicultores gaúchos e as concessionárias de energia elétrica no TJRS}

O posicionamento do TJRS nas diversas ações de indenização ajuizadas pelos fumicultores contra as concessionárias de energia elétrica vem sendo influenciado pela AED. Após 2016, essas ações, que tinham elevada probabilidade de sucesso para o fumicultor, passaram a ser decididas com base em conceitos dessa escola de pensamento, resultando em uma modificação do posicionamento do Tribunal, que passou a concluir

Rev. de Direito, Economia e Desenvolvimento Sustentável | e-ISSN: 2526-0057| Goiânia| v. 5 | n. 1 | p. 1-22 | Jan/Jun. 2019 
pela divisão do prejuízo entre os fumicultores e as concessionárias de energia elétrica, como será mostrado.

\section{a) As primeiras decisões}

As interrupções no fornecimento de energia elétrica pelas concessionárias prestadoras desse serviço público, durante muitos anos, têm levado os produtores de fumo no Rio Grande do Sul (RS) a ajuizar ações de indenização para buscar o ressarcimento dos prejuízos causados pela perda da safra de fumo ou desvalorização do produto pelos compradores.

Esses prejuízos decorrem da interrupção do fornecimento de energia elétrica no momento da secagem das plantas de fumo nas estufas elétricas, em geral, uma vez que bastam apenas duas horas sem energia para que o produto seja completamente danificado ou desvalorizado (desclassificado) para a venda (RIO GRANDE DO SUL, 2015).

É no verão o período mais intenso de colheita e secagem dessas folhas de fumo, o que coincide com a forte incidência de tormentas, ventanias, quedas de postes e interrupção de energia elétrica no estado. Com estradas rurais quase intransitáveis ou de trânsito lento, o conserto das linhas e a religação do serviço de fornecimento de energia elétrica demora bastante.

As ações de indenização contra as concessionárias de energia elétrica envolviam uma situação jurídica relativamente simples, uma vez que a má prestação desse serviço essencial e a interrupção do fornecimento de energia elétrica resultava em dano direto e imediato ao produtor rural, quando não caracterizavam caso fortuito ou de força maior. Portanto, a responsabilidade é objetiva, bastando a constatação do inadimplemento contratual, do dano e do nexo de causalidade, para surgir o direito à indenização, como versa o art. $37, \S 6^{\circ}$, da $\mathrm{CF} / 88$.

Essas ações de indenização, ajuizadas até o fim de 2016, tinham enorme probabilidade de sucesso para os fumicultores. Como consequência, observava-se, também, um crescente número de recursos interpostos pelas concessionárias de energia elétrica, significando elevada demanda judicial.

Rev. de Direito, Economia e Desenvolvimento Sustentável | e-ISSN: 2526-0057| Goiânia| v. 5 | n. 1 | p. 1-22 | Jan/Jun. 2019 
Muitas decisões condenavam as concessionárias a indenizar o produtor de fumo prejudicado pela interrupção do serviço no processo de secagem. Um exemplo é o da apelação cível n 70056574544 da Quinta Câmara Cível, comarca de Camaquã (RS). Em 25 de março de 2014, o colegiado seguiu, unanimemente, o entendimento da desembargadora Isabel Dias Almeida, relatora. $\mathrm{O}$ voto foi pelo desprovimento do recurso de apelação, mantendo a sentença de $1^{\circ}$ grau, que concluiu pela condenação da empresa ré e pagamento da indenização correspondente ao prejuízo sofrido pelo fumicultor, entre outras verbas:

Diante do exposto, JULGO PROCEDENTE a ação para condenar a ré a pagar à parte autora a quantia de $\mathrm{R} \$ 20.815,75$ (vinte mil, oitocentos e quinze reais e setenta e cinco centavos), com correção monetária pelo IGP-M a partir da data do laudo e juros de $1 \%$ ao mês a contar da citação. A ré pagará também as custas e despesas processuais devidas e os honorários advocatícios ao patrono da parte contrária, fixados em $15 \%$ sobre o valor da condenação, considerando o valor monetário envolvido na causa, o trabalho desempenhado nesses autos e os termos do art. 20, $3^{\circ}$, do CPC (RIO GRANDE DO SUL, 2014a, p. 2).

Os fundamentos jurídicos dessa decisão foram o art. 37, $\S 6^{\circ}$, da $\mathrm{CF} / 88$ e art. 22 do Código de Defesa do Consumidor (CDC). Dessa forma, foi aplicada à ré a mencionada teoria da responsabilidade objetiva, vez que presta serviço público de fornecimento de energia elétrica, previsto no art. $37, \S 6^{\circ}$, da $\mathrm{CF} / 88$.

Aplicou-se, também, o art. 22 do $\mathrm{CDC}$, que obriga órgãos públicos, suas empresas, concessionárias, permissionárias ou afins a fornecer serviços adequados, eficientes, seguros e, no caso de essenciais, contínuos. Assim, entendeu que a empresa ré deve assegurar de qualidade, segurança e eficiência da prestação desse serviço essencial, um dos grandes nortes das relações de consumo instituídos pelo CDC.

Na mesma linha tem-se a apelação cível no 70062723184 da Décima Câmara Cível, comarca de Camaquã (RS). O colegiado seguiu, unanimemente, o entendimento do relator, Jorge Alberto Schreiner Pestana que, em 18 de dezembro de 2014, assim se pronunciou:

O recurso não merece ser provido.

A responsabilidade da requerida ao presente caso é objetiva, à luz do que dispõe o art. 37, § $6^{\circ}$ da Constituição Federal, não sendo necessária a comprovação da culpa da Companhia ré para a configuração da responsabilidade civil. 
Aliado a isto, é de se ter que a concessionária de serviço é obrigada a fornecer serviços adequados, eficientes e seguros, consoante dispõe o art. 22 do Código de Defesa do Consumidor, sob pena de ter de reparar os danos causados aos consumidores (RIO GRANDE DO SUL, 2014b, p. 3-4).

No voto, o desembargador enfatiza, ainda, que a empresa concessionária, conhecedora da intensa demanda de energia elétrica para a atividade fumicultora, deveria evitar a interrupção do fornecimento, e não o produtor rural:

\begin{abstract}
Ainda, é de se ter que a falta de energia elétrica na região em decorrência da atividade desenvolvida pelos agricultores não pode ser fato atribuído exclusivamente ao consumidor, haja vista que, ainda que considerarmos que esta decorreu da sobrecarga dos aparelhos, é de se ter que a empresa demandada é sabedora da utilização de produtos destinados à secagem do fumo, sendo as exigências de consumo previsíveis e a interrupção do fornecimento em razão disso evitável.
\end{abstract}

Essas inúmeras ações resultavam em elevados valores pagos, anualmente, a título de indenização, pelas concessionárias de energia elétrica. Tal fato passou a causar preocupação de que as mesmas resultassem em despesas internalizadas na tarifa e, posteriormente, transferidas para os consumidores do estado, majorando o valor da conta.

Dessa forma, surgiu um debate entre os magistrados sobre os efeitos desses custos para as concessionárias e da possibilidade de se exigir que os fumicultores estivessem preparados para os problemas de interrupção do fornecimento de energia elétrica (RIO GRANDE DO SUL, 2018c).

Diante dessa possibilidade e da necessidade de buscar informações sobre diversas questões relativas ao recorrente problema, o Centro de Estudos do TJRS, promoveu, em 2015, um painel, no Projeto Debates sobre Temas Polêmicos, ouvindo representantes de diferentes setores da sociedade: Associação dos Fumicultores do Brasil (AFUBRA), Associação Brasileira de Distribuidores de Energia Elétrica (ABRADEE), Companhia Estadual de Energia Elétrica (CEEE), Instituto de Direito e Economia do Rio Grande do Sul (IDERS) e Instituto Brasileiro de Política e Defesa do Consumidor (BRASILCON). 
A provocação foi do Desembargador Eugênio Facchini Neto, Coordenador-

Geral do Centro de Estudos no biênio anterior, devido ao aumento do número de processos judiciais e da elevação das pretensões indenizatórias:

\begin{abstract}
os valores das indenizações têm sido cada vez mais altos - "impõe-se aprofundar o debate sobre até que ponto é razoável repassar tais custos para as concessionárias diante da alternativa de se exigir que os fumicultores estejam preparados para tais intempéries, porque seriam previsíveis," - porque acontecem todos os anos - "adquirindo geradores de energia que possam ser ativados em caso de interrupção da luz. Quais são os custos de tais providências? Qual a razoabilidade de tal exigência? É justo sempre repassar a outros os riscos inerentes à determinada atividade? É possível exigir-se de quem não pode sofrer interrupção do fornecimento de energia elétrica em sua atividade profissional que esteja preparado para as inevitáveis interrupções?" Os hospitais possuem esses geradores, porque, do contrário, se faltasse luz durante uma cirurgia, o paciente morreria na hora. "O que a análise econômica do Direito tem a dizer sobre isso? Quais seriam os custos exigidos dos fumicultores? Em caso positivo, de quem se poderia exigir tais providências? E as indústrias fumageiras teriam o dever de auxiliar os fumicultores na aquisição de tais geradores, se fosse o caso? (RIO GRANDE DO SUL, 2015b, p. 4).
\end{abstract}

O painel suscitou muito debate e trouxe relevantes informações que passaram a subsidiar as sentenças nos processos judiciais em questão. Interpretadas com base na AED, modificaram o entendimento de alguns desembargadores do TJRS, como será mostrado a seguir.

\title{
b) O debate promovido pelo Centro de Estudos do TJRS para subsidiar as sentenças nos processos judiciais entre os fumicultores e as concessionárias de energia elétrica
}

O painel destacou que a secagem do fumo pode ser efetuada em dois tipos de estufa: estufa convencional e estufa de ar forçado. No primeiro caso, trata-se de uma construção de alvenaria que utiliza o calor no interior, gerado pela queima de madeira, geralmente plantada pelo agricultor. No caso da estufa de ar forçado, há um equipamento automático de cura movido à energia elétrica, o que aumenta a capacidade de secagem e a economia de lenha, tornando esse tipo de estufa preferível: reduz o custo de produção, 
diminui a quantidade necessária de lenha (insumo) e proporciona um resultado mais eficiente para o produtor (RIO GRANDE DO SUL, 2015).

Destacou-se também que a indústria remunera o fumicultor pela qualidade do fumo, sendo a secagem na estufa, sem interrupção, determinante para tal. Esse processo é de melhor qualidade na estufa de ar forçado que, devido ao uso de controladores automáticos e distribuição adequada do calor, permite não apenas economia de lenha, como uma secagem mais uniforme.

Caso o produtor opte por construir uma estufa convencional, o dispêndio, geralmente custeado por ele, é de cerca de $\mathrm{R} \$ 18$ mil. Já a estufa de ar forçado pode ser financiada diretamente com uma empresa que vende e a instala. Nesse caso, a concessionária de energia deve autorizar e, devido à sobrecarga na rede, recomenda-se ter gerador próprio com chave automática. Essa informação, prestada pelo engenheiro agrônomo da AFUBRA, destaca a aquisição do gerador como uma indicação técnica ideal (RIO GRANDE DO SUL, 2015).

Adicionalmente, o engenheiro eletricista, representante da ABRADEE, destacou a "inevitabilidade das interrupções de energia elétrica, especialmente no meio rural" e a demora para o reparo, considerando que a rede de transmissão é aérea e, assim, sujeita a descargas elétricas, a danos causados pelas quedas de galhos, árvores e outros, durante fortes temporais (RIO GRANDE DO SUL, 2015, p. 46). Também se mostrou preocupado com o aumento do número de processos, em decorrência da distribuição de folders por escritórios de advocacia, incentivando as demandas judiciais: "A falta de energia por mais de uma hora gera direito de indenização" (BRASIL, 2015, p. 23).

Por fim, o engenheiro informou que, apesar de o gerador não ser obrigatório, reduz o risco da perda total ou parcial do fumo provocada pela interrupção do fornecimento de energia elétrica. O custo do gerador com sistema no-break que, em caso de interrupção da energia elétrica, acionável automaticamente para alimentar a estufa de ar forçado de secagem do fumo, é de quatro a seis mil reais, podendo ser financiado por dez anos, representando um dispêndio de quatrocentos a seiscentos reais por ano para o agricultor.

Rev. de Direito, Economia e Desenvolvimento Sustentável | e-ISSN: 2526-0057| Goiânia| v. 5 | n. 1 | p. 1-22 | Jan/Jun. 2019 


\section{c) O novo entendimento das decisões}

Com base no debate oportunizado pelo painel e em conceitos da AED, as decisões nas ações de indenização que, na maior parte dos casos, condenavam as concessionárias a pagar os prejuízos causados ao produtor de fumo afetado pela interrupção do serviço de fornecimento de energia elétrica no processo de secagem, foram modificadas. Desde 2016, passaram a expressar a preocupação dos magistrados com as externalidades negativas causadas pelo desembolso, pelas concessionárias de energia elétrica, de valores crescentes para indenizações dos fumicultores, uma vez que tais despesas seriam internalizadas na tarifa a ser paga por todos os consumidores do serviço no Rio Grande do Sul.

O novo entendimento, adotado inicialmente na $9^{\mathrm{a}}$ câmara cível, seguido pela $10^{\mathrm{a}}$ câmara cível do mesmo TJRS, argumenta que os fumicultores poderiam evitar os danos a sua atividade a um custo menor, devendo adquirir geradores com sistema no-break acionáveis automaticamente, no caso de interrupção de energia, destacando que, na estufa de ar forçado, o "gerador próprio com chave automática" (BRASIL, 2015, p. 11) é recomendado pela empresa que vende e instala o equipamento.

As decisões invocam ideias, doutrinas e institutos jurídicos fundados na Common Law, no instituto do duty to mitigate the loss (dever de mitigar os prejuízos), na ideia do cheapest cost avoider (evitador de maior custo), na Fórmula Hand e no encargo de evitar o próprio dano.

Dessa forma, o entendimento passou a assim ser resumido:

Fundamentalmente entende-se que os fumicultores que se utilizam de estufas elétricas têm o encargo de adquirirem geradores dotados do sistema no-break, acionáveis automaticamente em caso de interrupção da energia elétrica. A essa conclusão se chega diante do fato de que as intempéries são inevitáveis, as interrupções de energia são previsíveis e o custo para aquisição de um gerador é relativamente baixo, comparado com os previsíveis danos (FACCHINI NETO, 2017, p. 250).

Assim, a $9^{\text {a }}$ Câmara Cível do TJRS reformou diversas sentenças que condenavam a concessionária de energia elétrica a indenizar o produtor de fumo prejudicado pela interrupção do serviço no processo de secagem, considerando que as

Rev. de Direito, Economia e Desenvolvimento Sustentável | e-ISSN: 2526-0057| Goiânia| v. 5 | n. 1 | p. 1-22 | 
intempéries são inevitáveis, as interrupções de energia previsíveis e o custo de adquirir um gerador é relativamente baixo, em comparação aos danos.

É o que ser observa em várias decisões da Câmara, como na apelação cível $n^{\circ}$ 70069954626, Comarca de Macau (RS); apelação cível no 70070198742, comarca de Arvorezinha (RS); apelação cível no 70079977690, comarca de Camaquã (RS); apelação cível n 70079828943, comarca de Camaquã (RS); apelação cível n ${ }^{\circ} 70079847059$, comarca de Camaquã (RS); apelação cível no 70080022213, comarca de São Lourenço do Sul (RS); dentre muitas outras.

Todas concluem pela divisão do prejuízo entre os fumicultores e as concessionárias de energia elétrica, a exemplo da apelação cível n ${ }^{\circ}$ 70075864108, comarca de Venâncio Aires, de 13 de dezembro de 2017:

Por todos os fundamentos acima alinhavados, em situações como a da espécie sob análise, entendo ser razoável que os fumicultores absorvam 2/3 do prejuízo que sofreram, devendo o terço restante ser suportado pela concessionária de energia elétrica (RIO GRANDE DO SUL, 2017, p. 35).

O colegiado seguiu, unanimemente, o entendimento do desembargador Eugênio Facchini Neto, relator, de que a concessionária de energia elétrica deve suportar apenas o terço restante dos danos, restringindo-se aos casos de que a interrupção ininterrupta não seja superior a 24 horas, o que passaria a exigir geradores mais potentes ou grandes reservas de combustível para o funcionamento dos geradores nas estufas de secagem das plantas de fumo.

A doutrina do duty to mitigate the loss (dever de mitigar os prejuízos), invocada nesse entendimento, apesar de originária da Common Law, é compatível com o ordenamento jurídico brasileiro, sendo possível a um magistrado brasileiro julgar uma demanda com base em institutos, ideias e doutrinas alienígenas, não positivadas no ordenamento pátrio, argumentam os votos nas decisões em análise (FACCHINI NETO, 2017).

O dever de mitigar os prejuízos, doutrina desenvolvida pelo direito norteamericano, requer que o titular de um direito, o credor, sempre que possível, atue para minimizar a extensão do dano, evitando que a situação se agrave (VILAS-BÔAS, 2013).

Rev. de Direito, Economia e Desenvolvimento Sustentável | e-ISSN: 2526-0057| Goiânia| v. 5 | n. 1 | p. 1-22 | Jan/Jun. 2019 
O princípio da boa-fé objetiva é que fundamenta o dever de mitigar, reivindicando a necessidade de colaboração do credor para restringir o prejuízo ao menor dano possível. No caso de a parte em posição de vantagem negligenciar providências para mitigar os prejuízos, a parte devedora pode pedir a redução das perdas e danos, com base no total da perda que poderia ter sido diminuída (FACCHINI NETO, 2017).

Nas apelações em análise, o dever de mitigar os prejuízos foi invocado para evitar os danos, e não para mitigar. Portanto, o colegiado entendeu que os fumicultores também deveriam ter adotado medidas que prevenissem os danos, tendo os fumicultores concorrido para os riscos.

Outra doutrina utilizada foi a do cheapest cost avoider (evitador de maior custo), tendo as decisões buscado um critério objetivo para minimizar perdas e custos e para identificar a parte em melhores condições, do ponto de vista econômico, de evitar esse dano. $\mathrm{O}$ voto do desembargador Eugênio Facchini Neto, relator da apelação cível $\mathrm{n}^{\circ}$ 70069954626, comarca de Marau (RS), em 14 de dezembro de 2016, conclui que os fumicultores poderiam evitar os danos a um custo menor:

Trata-se de um sistema perverso e economicamente irracional. Se os
fumicultores, pela especificidade do cultivo a que se dedicam, não
podem sofrer interrupção de energia elétrica no momento mais crítico
da secagem do seu produto; se essa interrupção de energia é quase
inevitável, cedo ou tarde, diante das intempéries climáticas a que
estamos sujeitos no período do verão; se tais prejuízos podem ser
evitados mediante a instalação de um gerador tipo nobreak; se isso é
possível ser feito a relativamente baixo custo, como se constatou
durante o painel a que se aludiu anteriormente; então disso tudo decorre
que é razoável exigir-se que os fumicultores adotem tal providência
para evitar os danos, em nome da racionalidade econômica e jurídica a
que se referiu acima (RIO GRANDE DO SUL, 2016a, p. 36).

Os votos destacam o argumento de Guido Calabresi para a AED, segundo o qual, para identificar quem pode evitar de maneira mais econômica o custo dos acidentes, devese buscar aquele que possui o maior grau possível de internalização dos custos (FACCHINI NETO, 2017). As decisões tradicionais permitiam que o fumicultor repassasse seu prejuízo para as concessionárias de energia elétrica e essas, ao incorporarem os prejuízos no valor das tarifas, repassavam os prejuízos sofridos pelos fumicultores a todos os consumidores de energia elétrica.

Rev. de Direito, Economia e Desenvolvimento Sustentável | e-ISSN: 2526-0057| Goiânia| v. 5 | n. 1 | p. 1-22 | Jan/Jun. 2019 
Dessa forma, a AED permitiu a alteração do entendimento tradicional de acolhimento integral dos danos materiais, passando as decisões a concluir pela divisão do prejuízo entre esses e as concessionárias de energia elétrica.

O método da AED permitiu o uso da fórmula Hand nas decisões em análise, utilizado originalmente pelo juiz Learned Hand, em 1947, como critério objetivo de aferição da culpa. A fórmula compara o custo do investimento necessário para evitar o dano (B) com o valor desses danos (L), multiplicado pela probabilidade (P) de que venha a ocorrer. Quando "B $<$ PL", conclui-se pela responsabilidade (CABRAL; REICHEL, 2017).

As decisões trazem uma adaptação dessa fórmula e fundamentam-se no art. 945 do Código Civil Brasileiro (Lei no 10.406 de 10 de Janeiro de 2002), o qual institui que, quando "a vítima tiver concorrido culposamente para o evento danoso, a sua indenização será fixada tendo-se em conta a gravidade de sua culpa em confronto com a do autor do dano".

O voto do relator na apelação cível no 70080022213 , comarca de São Lourenço do Sul, em 18 de dezembro de 2018, destaca a "culpa da vítima ao não adotar as providências cabíveis e razoáveis, sugeridas pelas circunstâncias, para evitar ou minorar o seu próprio prejuízo" (RIO GRANDE DO SUL, 2018d, p. 28). Para a caracterização da culpa, aplica a fórmula Hand ao caso concreto e conclui que os fumicultores teriam agido de forma negligente, pois não investiram "quantia relativamente módica, para evitar danos potencialmente maiores" (p. 30) e poderiam ter evitado as consequências negativas, instalando um gerador de corrente.

O custo da aquisição do gerador pelos fumicultores foi estimado entre 4 mil e 6 mil reais no painel promovido pelo Centro de Estudos do TJRS, em 2015, e que passou a subsidiar as sentenças nos processos judiciais em questão (RIO GRANDE DO SUL, 2015). Por outro lado, cada caso julgado na Nona Câmara Cível representava valores que ultrapassavam R \$10 mil em indenizações a serem pagas pelas concessionárias de energia elétrica, impactando no valor das tarifas pagas pelos consumidores:

Por tudo isso, considerando que somente esta Nona Câmara Cível julga, a cada sessão, cerca de uma dezena de casos semelhantes, cujos valores individuais muitas vezes superam os dez mil reais (alguns casos superam os trinta mil reais), tem-se uma ideia do total da conta que,

Rev. de Direito, Economia e Desenvolvimento Sustentável | e-ISSN: 2526-0057| Goiânia| v. 5 | n. 1 | p. 1-22 | Jan/Jun. 2019 
anualmente, é repassada para as concessionárias de energia elétrica num primeiro momento. Num segundo momento, tais indenizações transformam-se em custos, são contabilizadas e, cedo ou tarde, internalizadas em forma de elevação da tarifa. E, quando isso acontece - e isso fatalmente acaba acontecendo, seguindo a lógica do regime capitalista -, todos os consumidores são chamados a pagar essa conta (RIO GRANDE DO SUL, 2018d, p. 51).

Então, a aplicação da fórmula Hand, conclui que há um elevado custo social em comparação ao custo da aquisição do equipamento, e pela responsabilidade dos fumicultores, uma vez que é (praticamente) impossível não haver, no verão chuvoso e com fortes tempestades, interrupções no fornecimento de energia elétrica.

Por fim, as decisões também se fundamentam na figura do encargo, da doutrina portuguesa e do direito alemão, e numa interpretação dos artigos 402, 403 e 945 do Código Civil brasileiro: os fumicultores, ao não adequarem suas condutas de modo a evitar o próprio dano ou o seu agravamento, perderiam parcialmente, o direito à indenização pelo respectivo dano que poderiam ter evitado sofrer. Em consequência, ainda que não se trate de um dever jurídico, é um encargo incumbente aos mesmos providenciarem a instalação de um gerador, a fim de evitar e/ou minorar os previsíveis prejuízos a que estão expostos. Ao não adotarem tal providência "devem suportar os ônus decorrentes da sua omissão, com redução do valor da indenização a que fazem jus" (RIO GRANDE DO SUL, 2018b, p. 42).

No entanto, os ônus da interrupção da energia elétrica não cabem somente aos fumicultores, como explicitamente mencionado nos votos, como faz o relator Des. Eugênio Facchini Neto, na apelação cível no 70079977690, de 18 de dezembro de 2018, devendo parte ser suportada pela concessionária de energia elétrica.

Ressalte-se, ainda, que o Tribunal argumenta que esse novo posicionamento não desconsidera "os interesses do consumidor específico (o fumicultor), pregando-se a volta do lamentável caveat emptor"1 (RIO GRANDE DO SUL, 2018a, p. 43). Com base na $\mathrm{AED}$, considera que o posicionamento procura proteger os interesses da generalidade dos usuários de energia elétrica, os quais arcarão com maiores custos da tarifa. Ficam, porém, algumas indagações, a serem respondidas em próximos estudos: a decisão fundamentou-

\footnotetext{
${ }^{1}$ Pela regra do caveat emptor, compete ao consumidor informar-se para resguardar-se de eventuais danos.
}

Rev. de Direito, Economia e Desenvolvimento Sustentável | e-ISSN: 2526-0057| Goiânia| v. 5 | n. 1 | p. 1-22 | 
se em apenas uma fonte? Não deveria a mudança de entendimento analisada usar a metodologia da AED apoiada em dados de fontes diversificadas?

\section{4- Considerações finais}

$\mathrm{O}$ artigo mostrou a aplicação da metodologia da AED no posicionamento de magistrados em decisões judiciais envolvendo os fumicultores gaúchos e as concessionárias de energia elétrica no TJRS. Observou-se que essas passaram a ser fundamentadas em influências extrajurídicas, decorrentes do uso de princípios baseados na racionalidade econômica propostos pela AED.

As ações ajuizadas pelos fumicultores tinham elevada probabilidade de sucesso para os mesmos, sendo fundamentadas no art. 37, $\S 6^{\circ}$, da $\mathrm{CF} / 88$, e no art. 22 do Código de Defesa do Consumidor (CDC), aplicando-se a teoria da responsabilidade objetiva.

Desde 2016 essas ações passaram, cada vez mais, a ser decididas com base em conceitos da AED, concluindo o TJRS pela divisão do prejuízo entre os fumicultores e as concessionárias de energia elétrica. Divergentes no início, os votos mostram que o colegiado buscou um entendimento que passasse a ser de todo o Tribunal. A busca pela unanimidade pretendia evitar que, respeitadas as particularidades de cada caso, a composição do colegiado trouxesse soluções diversas para casos substancialmente idênticos, ferindo o princípio da isonomia (RIO GRANDE DO SUL, 2016b).

Inicialmente, esse entendimento foi adotado na $9^{\mathrm{a}}$ câmara cível, seguido pela $10^{\mathrm{a}}$ câmara cível do Tribunal após 2017, usando conceitos como o dever de mitigar os prejuízos, a ideia de evitador de maior custo e a Fórmula Hand, bem como o encargo de evitar o próprio dano.

As decisões passaram a evidenciar a importância da AED no julgamento das ações do TJRS envolvendo os conflitos entre os fumicultores e as empresas concessionárias de energia elétrica, buscando considerar aspectos econômicos e a maior eficiência. Nesse sentido, entenderam ser economicamente racional exigir que esses fumicultores adquiram geradores de energia para a secagem do fumo, evitando os previsíveis danos provocados pela interrupção do fornecimento do serviço.

Rev. de Direito, Economia e Desenvolvimento Sustentável | e-ISSN: 2526-0057| Goiânia| v. 5 | n. 1 | p. 1-22 | 
A avaliação custo/benefício trazida pelas decisões mostra que o Tribunal argumentou ser importante considerar o bem-estar dos consumidores de energia elétrica no estado, uma vez que, segundo as mesmas, o preço das tarifas cobradas pelas empresas concessionárias deveria aumentar em decorrência das indenizações conferidas pelas decisões tradicionais.

Assim, visando uma decisão mais racional, socialmente eficiente e equânime, passível de interferir no comportamento futuro dos agentes econômicos, o TJRS entendeu que os fumicultores poderiam evitar os danos a sua atividade a um custo menor, com a aquisição dos mencionados geradores. Porém, é importante ressaltar que a mudança para esse entendimento poderá ter impactos negativos sobre os produtores rurais, uma vez que a atividade é tipicamente familiar. A fonte de renda das famílias provém fundamentalmente da agricultura, notadamente de um produto específico, o fumo; a força de trabalho é basicamente familiar; e a atividade se desenvolve em pequenas áreas.

Preocupa o fato de que muitas informações usadas nessas decisões tiveram como fonte apenas relatos prestados no debate promovido pelo Centro de Estudos do TJRS. Os acórdãos reiteradamente mencionam que o custo para aquisição de um gerador é relativamente baixo, ficando em torno de quatro a seis mil reais e podendo ser financiado por dez anos. Contudo, outros estudos técnicos parecem ser necessários para fundamentar essas conclusões, uma vez que, sendo esses produtores de pequeno porte, uma avaliação mais acurada talvez pudesse ser capaz de melhor aferir a viabilidade de os mesmos absorverem os custos adicionais dessa aquisição.

Por outro lado, sendo muito rentáveis as aplicações financeiras em ações das empresas do setor elétrico, além de pouco voláteis e seguras, emerge uma dúvida: não seriam essas empresas mais capazes de suportar a elevação de custos que os agricultores e realizar os investimentos necessários para assegurar ao consumidor a qualidade do serviço contratado?

Assim, a mesma racionalidade econômica aplicada ao fumicultor da AED para justificar que o problema de falha no fornecimento de energia elétrica é previsível deve ser considerada para essas empresas. Os acórdãos concluem que cabe ao fumicultor arcar com custos adicionais, apesar de já ter contrato o serviço de energia. Porém, como a mesma previsibilidade deve ser apreciada pelas empresas concessionárias, elas precisam

Rev. de Direito, Economia e Desenvolvimento Sustentável | e-ISSN: 2526-0057| Goiânia| v. 5 | n. 1 | p. 1-22 | Jan/Jun. 2019 
fazer a manutenção constante de sua rede elétrica, efetuando melhorias e prestando adequadamente o serviço aos consumidores que dela dependem, em todas as épocas do ano.

Deste modo, conclui-se que a mudança de entendimento do TJRS nos casos em estudo, ao aplicar a metodologia da AED, deve estar apoiada em dados coletados em fontes diversificadas, minimizando as possibilidades de que vieses prejudiquem a busca por justiça daqueles que procuram o Judiciário.

\section{5- Referências}

BRASIL. Superior Tribunal de Justiça (STJ). Recurso Especial $\mathbf{n}^{\mathbf{0}}$ 1163283/RS. Processual civil. Contratos de financiamento imobiliário. Sistema Financeiro de Habitação. Lei 10931/2004. Inovação. Requisitos para a petição inicial. Relator Ministro Luis Felipe Salomão, quarta turma, 07 de abril de 2015.

CABRAL, Flávio Garcia; REICHEL, Dafne. Breves Considerações sobre a Fórmula de Hand e sua Aplicação à Responsabilidade dos Agentes Públicos. Revista da PGBC, Brasília, v. 11, n. 1, p. 37-56, 2017.

CEBOLÃO, Karla Azevedo. A justiça é eficiente? Discutindo a Análise Envoltória de Dados (DEA) na avaliação dos tribunais de justiça estaduais brasileiros. $136 \mathrm{f}$. Dissertação (Mestrado em Direito, Políticas Públicas e Desenvolvimento), Centro Universitário do Estado do Pará, Belém, 2017.

COELHO, Cristiane de Oliveira. A Análise Econômica do Direito enquanto Ciência: uma explicação de seu êxito sob a perspectiva da História do Pensamento Econômico. Latin American and Caribbean Law and Economics Association (ALACDE) Annual Papers, 2007. Disponível em: https://escholarship.org/uc/item/47q8s2nd\#page-1. Acesso em: 28 de jun. de 2016.

ESTEVES, Heloisa Borges Bastos. Economia e Direito: um diálogo possível. Rio de Janeiro, 2010, 252f. Tese de Doutorado. Universidade Federal do Rio de Janeiro (Programa de Pós-Graduação Economia).

FACCHINI NETO, Eugênio. Duty to mitigate the loss: cheapest cost avoider: hand formula: aplicação judicial brasileira de doutrina e jurisprudência estrangeiras: $o$ positivismo jurídico em um mundo globalizado. Revista de Direito Civil Contemporâneo, São Paulo, Ed. RT, vol. 13, ano 4, p. 249-279, 2017.

Rev. de Direito, Economia e Desenvolvimento Sustentável | e-ISSN: 2526-0057| Goiânia| v. 5 | n. 1 | p. 1-22 | 
FERREIRA, Bráulio Cavalcanti; QUEIROZ, Bruna Pamplona de; GONÇALVES, Everton das Neves. Análise Econômica do Direito e o Compliance Empresarial: Apreciação jurídico-econômica dos programas de conformidade e dos custos de prevenção. Economic Analysis of Law Review, v. 9, nº 1, p. 259-276, 2018.

OLIVEIRA, Paulo Fernando de Lima. A análise econômica do Direito chega ao STJ. 2015. Disponível em https://jus.com.br/artigos/40952/a-analise-economica-do-direitochega-ao-stj. Acesso em: 30 jan. 2019.

POSNER, Richard A. The economics of justice. $2^{\text {nd }}$ edition. Cambridge, Massachusetts: Harvard University Press, 1983.

RIO GRANDE DO SUL. Tribunal de Justiça do Estado. Apelação cível no 70069954626. Ação de indenização. Secagem de Fumo. Interrupção do fornecimento de Energia elétrica. Pretensão indenizatória acolhida apenas em parte. Repartição dos riscos. Alteração do Entendimento jurisprudencial. Relator Des. Eugênio Facchini Neto, 14 de dezembro de 2016a.

RIO GRANDE DO SUL. Tribunal de Justiça do Estado. Apelação cível no 70075864108. Ação de indenização. Secagem de fumo. Interrupção do fornecimento de energia elétrica. Pretensão indenizatória acolhida apenas em parte. Repartição dos riscos. Alteração do entendimento jurisprudencial. Relator: Eugênio Facchini Neto, 13 de dezembro de 2017.

RIO GRANDE DO SUL. Tribunal de Justiça do Estado. Apelação cível no 70079828943. Ação de indenização. Secagem de fumo. Interrupção do fornecimento de energia elétrica. Pretensão indenizatória acolhida apenas em parte. Repartição dos riscos. Entendimento jurisprudencial alterado. Relator Des. Eugênio Facchini Neto, 18 de dezembro de 2018a.

RIO GRANDE DO SUL. Tribunal de Justiça do Estado. Apelação cível no 70070198742. Pretensão indenizatória parcialmente acolhida no caso. Alteração do entendimento jurisprudencial. Relator Des. Eugênio Facchini Neto, 14 de dezembro de 2016b.

RIO GRANDE DO SUL. Tribunal de Justiça do Estado. Apelação cível n 70056574544. Interrupção do fornecimento de energia elétrica. Perda de qualidade de fumo. Nexo causal caracterizado. Danos materiais caracterizados. Relatora: Isabel Dias Almeida, 25 de março de 2014a.

RIO GRANDE DO SUL. Tribunal de Justiça do Estado. Apelação cível n 70062723184. Responsabilidade civil. Suspensão do serviço de fornecimento de energia elétrica. Responsabilidade objetiva. Secagem de fumo. Prejuízos. Negado Provimento À Apelação. Unânime. Relator: Jorge Alberto Schreiner, 18 de dezembro de 2014b.

RIO GRANDE DO SUL. Tribunal de Justiça do Estado. Apelação cível no 70079977690. Ação de indenização. Secagem de fumo. Interrupção do fornecimento de energia elétrica. Dever do fumicultor de adotar providência para evitar o dano. Especificidade de sua cultura agrícola. Necessidade de instalação de gerador próprio. Duty to mitigate the loss. "Hand formula". Cheapest cost avoider. Encargo de evitar o próprio dano. Pretensão

Rev. de Direito, Economia e Desenvolvimento Sustentável | e-ISSN: 2526-0057| Goiânia| v. 5 | n. 1 | p. 1-22 | Jan/Jun. 2019 
indenizatória acolhida apenas em parte. Repartição dos riscos. Entendimento jurisprudencial alterado. Relator Des. Eugênio Facchini Neto, 18 de dezembro de 2018b.

RIO GRANDE DO SUL. Tribunal de Justiça do Estado. Apelação cível no 70079847059. Ação de indenização. Secagem de fumo. Interrupção do fornecimento de energia elétrica. Dever do fumicultor de adotar providência para evitar o dano. Especificidade de sua cultura agrícola. Necessidade de instalação de gerador próprio. Duty to mitigate the loss. "Hand formula". Cheapest cost avoider. Encargo de evitar o próprio dano. Pretensão indenizatória acolhida apenas em parte. Repartição dos riscos. Entendimento jurisprudencial alterado. Relator Des. Eugênio Facchini Neto, 18 de dezembro de 2018c.

RIO GRANDE DO SUL. Tribunal de Justiça do Estado. Apelação cível no 70080022213. Ação de indenização. Secagem de fumo. Interrupção do fornecimento de energia elétrica. Dever do fumicultor de adotar providência para evitar o dano. Especificidade de sua cultura agrícola. Necessidade de instalação de gerador próprio. Duty to mitigate the loss. "Hand formula". Cheapest cost avoider. Encargo de evitar o próprio dano. Pretensão indenizatória acolhida apenas em parte. Repartição dos riscos. Entendimento jurisprudencial alterado. Relator Des. Eugênio Facchini Neto, 18 de dezembro de 2018d.

RIO GRANDE DO SUL. Tribunal de Justiça do Estado. Responsabilidade civil pela interrupção de fornecimento de energia elétrica e o caso dos fumicultores - um debate sobre a justiça da divisão de riscos. Porto Alegre, 2015. Disponível em: https://www.tjrs.jus.br/site/poder_judiciario/tribunal_de_justica/centro_de_estudos/ temas_polemicos.html. Acesso em: 22 jan. 2019.

SALAMA, Bruno Meyerhof. A história do declínio e queda do eficientismo na obra de Richard Posner. 2010. Disponível em: https://works.bepress.com/ bruno_meyerhof_salama/35/.Acesso em: 27 de jun. de 2016.

SALAMA, Bruno Meyerhof. O que é pesquisa em Direito e Economia? Cadernos Direito GV, v. 5, n. 2, p. 4- 58, 2008.

TIMM, Luciano Benetti (Org.). Direito e economia no Brasil. São Paulo: Atlas, 2012.

VILAS-BÔAS, Renata Malta. Duty to mitigate the loss no Direito Civil pátrio. Revista Âmbito Jurídico, n. 111, Ano XVI, n.p., 2013. Disponível em: http://ambitojuridico.com.br/site/?n_link=revista_artigos leitura\&artigo id=12702. Acesso em: 15 jan. 2019. 